\title{
Scleromyxedema: a case report with cutis-laxa like features
}

\begin{abstract}
Scleromyxedema is an uncommon disease that corresponds to the generalized form of lichen myxedematosus. It is clinically characterized by generalized papules with skin infiltration. Histopathology reveals a triad including mucin deposition, fibrosis and irregularly arranged fibroblastic proliferation. This disease presents multiple extracutaneous manifestations and is associated with other diseases, especially paraproteinemia. We present the case of a 75 year-old woman, who presented a scleromyxedema with cutis-laxa like features. These cutaneous changes are infrequently seen and have been recently described in the context of scleromyxedema.
\end{abstract}

Volume 3 Issue I - 2018

\author{
Molgó M, Hermosilla N, Navajas-Galimany L, \\ Pilcante J and González S \\ Department of Dermatology and Pathology, Pontificia \\ Universidad Católica de Chile, Chile
}

Correspondence: Montserrat Molgó, Departments of Dermatology and Pathology, Faculty of Medicine, Pontificia Universidad Católica de Chile, Santiago, Chile, Email lfnavaja@uc.cl

\section{Introduction}

Scleromyxedema is a generalized form of myxedematous lichen, a chronic cutaneous mucinosis of unknown cause, usually associated with monoclonal gammopathy and other underlying systemic disorders. It is characterized by lichenoid papules and diffuses induration of the skin. Both clinical and histopathological cutis-laxa changes have been recently described in this entity. We present a case that exhibited these findings.

\section{Case presentation}

A 75 year-old woman who reports eight months of painful lesions located in her face (Figure 1) back and thighs. On physical examination she presented multiple erythematous plaques and grouped papules, as well as skin infiltration, highlighting the presence of excessive folding on the back and posterior areas of both thighs (Figure 2). Several skin biopsies showed a normal epidermis, dermis with diffuse mucinosis, and numerous fibroblasts and scattered histiocytes without atypia, consistent with scleromyxedema. Protein electrophoresis and immunofixation in blood were compatible with multiple myeloma. This study was performed at Red Salud UC-Christus, Santiago, Chile by the Department of Dermatology. The patient was referred to a hemato-oncologist of our institution for the treatment of her myeloma. She allowed us to publish her case.

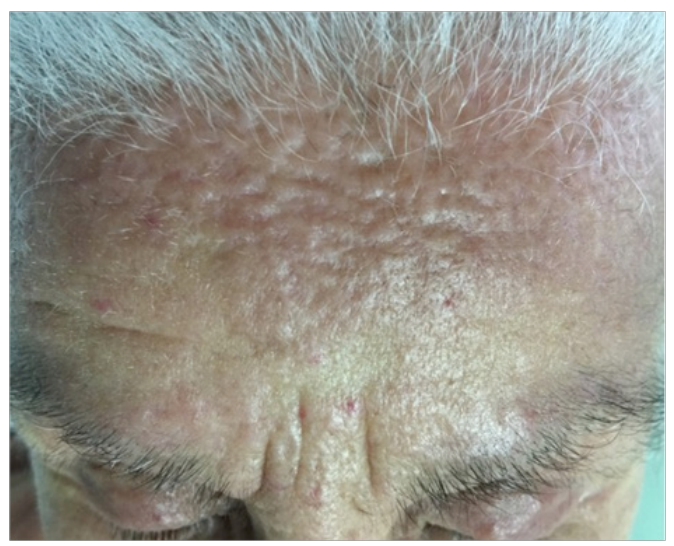

Figurel: Leonine facie.

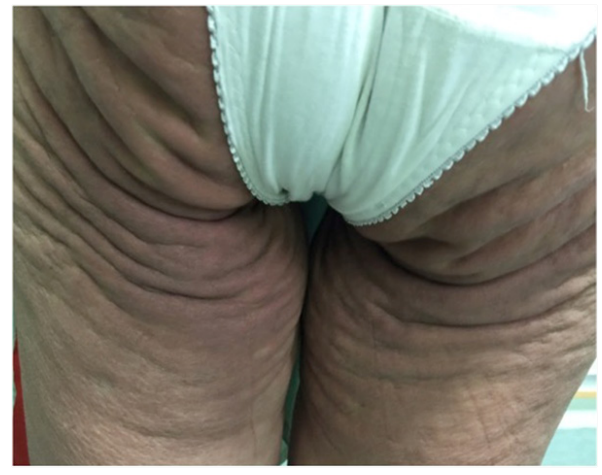

Figure 2: Excessive folding in the posterior areas of thighs.

\section{Discussion}

Scleromyxedema is one of the four types of lichen myxedematosus, corresponding to its generalized form. ${ }^{1}$ It typically affects middleaged adults, with no predilection for sex. This disease is uncommon and its diagnosis is usually delayed. A multicenter study of 30 patients with scleromyxedema reported that the mean age of presentation was 59 years, and the average time from onset of this disease to diagnosis was nine months. ${ }^{2}$

The pathophysiology of scleromyxedema remains unclear. It has been described that fibroblasts of patients with this disease synthesize more hyaluronic acid than normal and, subsequently, more mucin. ${ }^{3}$ In vitro studies have shown that the serum of patients with scleromyxedema stimulate the proliferation of dermal fibroblasts ${ }^{3}$ producing more hyaluronic acid and prostaglandin E. ${ }^{4}$ Although $83 \%$ of patients with scleromyxedema have an IgG gammopathy, isolated IgG peaks in serum do not determine fibroblastic proliferation. This suggests that "non-paraprotein factors" could be responsible for that reaction. The main hypothesis is that circulating cytokines such as IL-1, TNF-alpha and TGF-beta, which are known to stimulate glycosaminoglycan synthesis and fibroblast proliferation in the skin, could play a role. ${ }^{5}$

Scleromyxedema is characterized by widespread symmetric eruption of small, waxy, firm papules that are closely spaced and often 
arranged in a linear pattern. Papules are typically 2 to $3 \mathrm{~mm}$ in size, dome shaped or flat topped. The most affected areas are the face, neck, distal forearms, and hands. The palms, scalp, and mucous membranes are spared. Affected skin may exhibit diffuse erythema, edema, and a brownish discoloration. Unlike scleroderma, telangiectasias and calcinosis are not present and Raynaud's phenomenon is uncommon. Eyebrow, pubic and axillary hair may be sparse. ${ }^{6}$ Lesions can be pruritic and Koebner phenomenon in response to scratching has been described. Leonine facies may be observed in patients with diffuse mucin deposition within the glabella. Thickening of the proximal interphalangeal joints with central depression has been described as the "doughnut sign". Patients with scleromyxedema frequently present with skin stiffness and decreased range of motion of hands, lips, and extremities. ${ }^{7}$ Another characteristic finding is the "Shar-pei sign", described as deep furrows on the back of the patient. ${ }^{2}$

Cutis-laxa like features have been recently described in some patients with scleromyxedema. Gonzalez et al. ${ }^{8}$ performed a retrospective study of 19 patients, in which $37 \%$ of them had cutislaxa like changes, highlighting that in all these patients, it was the primary clinical finding. These were described as symmetric and most notable on the back, arms, and knees, and were not always associated with classical cutaneous features. ${ }^{8}$

The extracutaneous manifestations of scleromyxedema are serious and could be fatal in some cases. The pathogenesis of these manifestations remains unclear. It has been suggested by some researchers that mucin deposition in various organs may be the cause. Dysphagia is the most common extracutaneous manifestation of scleromyxedema. Others systemic manifestations are: neurological involvement, heart failure, nasal regurgitation, mastication difficulty, hoarseness and aspiration (as a result of laryngeal involvement), pulmonary hypertension, cor pulmonale, myopathy (presenting as proximal muscle weakness), renal failure and arthralgia.? Scleromyxedema is associated almost always with paraproteinemia $(83.2 \%-100 \%)$ with a progression to multiple myeloma in only $10 \%$ of cases.

Among the histopathologic findings of scleromyxedema there are irregularly arranged fibroblasts and diffuse mucin deposition within the upper and mid reticular dermis. Fibroblasts produce large amount of collagen, which is small in diameter. Elastic fibers are decreased in quantity, the epidermis may be thinned and hair follicles may be atrophic. A slight perivascular, superficial lymphocytic and plasmacytic infiltrate may be present. ${ }^{1}$ In addition Gonzalez et al. describe that in all the studied patients, elastic fibers were fragmented or with decreased density which are compatible findings with cutislaxa like features. ${ }^{8}$

The diagnosis of scleromyxedema is clinicopathologic. The recently published guideline on the diagnosis and treatment of sclerosing diseases of the skin developed by the European Dermatology Forum, proposes the following diagnostic criteria: ${ }^{9}$

a. Generalized/diffuse papular and sclerodermoid eruption

b. Microscopic triad, including mucin deposition (composed primarily of hyaluronic acid in the upper and mid-reticular dermis), fibrosis and irregularly arranged fibroblast proliferation.

c. Monoclonal gammopathy

d. Absence of thyroid disorder
Regarding the treatment, evidence available in literature is scarce given the low prevalence of this disease. Most treatments used are based on case reports and case series. First line treatment is systemic therapy with intravenous immunoglobulin (IV Ig), although the mechanism of action is unknown. Case reports and case series have demonstrated improvement of cutaneous and extracutaneous signs and symptoms of scleromyxedema during IV Ig therapy, and appears to be well tolerated. ${ }^{2,10}$ Second line treatment is thalidomide (or lenalidomide) and systemic glucocorticoids. This treatment can be given alone or in combination with IV Ig. ${ }^{11,12}$ Some reports have shown response to melphalan plus autologous hematopoietic stem cell transplant and bortezomib plus dexamethasone. ${ }^{13,14}$

\section{Conclusion}

We presented a clinical case of a patient with scleromyxedema, in which her main findings were the cutis-laxa features. These findings have been recently described in several patients with scleromyxedema. We think it is important to remark this particular clinical presentation, since this type of cutaneous manifestation may not coexist with the classically described findings, delaying or even misleading the diagnosis.

\section{Acknowledgements}

None.

\section{Conflict of interest}

The authors have no conflict of interest.

\section{References}

1. Rongioletti F, Rebora A. Updated classification of papular mucinosis, lichen myxedematosus, and scleromyxedema. J Am Acad Dermatol. 2001;44(2):273-281.

2. Rongioletti F, Merlo G, Cinotti E, et al. Scleromyxedema: a multicenter study of characteristics, comorbidities, course, and therapy in 30 patients. J Am Acad Dermatol. 2013;69(1):66-72.

3. White GM, Jeffes EW. Stimulation of fibroblasts by paraprotein in scleromyxedema. J Am Acad Dermatol. 1989;21(4):816.

4. Yaron M, Yaron I, Yust I, et al. Lichen myxedematosus (scleromyxedema) serum stimulates hyaluronic acid and prostaglandin E production by human fibroblasts. J Rheumatol. 1985;12(1):171-175.

5. Rongioletti F. Lichen myxedematosus (papular mucinosis): new concepts and perspectives for an old disease. Semin Cutan Med Surg. 2006;25(2):100-104.

6. Harris AO, Altman AR, Tschen JA, et al. Scleromyxedema. Int $J$ Dermatol. 1989;28(10):661-667.

7. Cokonis GCD, Falasca G, Georgakis A, et al. Scleromyxedema. Clin Dermatol. 2006;24(6):493-497.

8. Gonzalez STM, Lehman JS, Buonaccorsi JN, et al. Frequency of cutis laxalike clinical features and elastolysis in scleromyxedema: a retrospective clinicopathologic study of 19 patients with scleromyxedema. J Cutan Pathol. 2016;43(3):246-251.

9. Knobler R, Moinzadeh P, Hunzelmann N, et al. European dermatology forum S1-guideline on the diagnosis and treatment of sclerosing diseases of the skin, Part 2: Scleromyxedema, scleredema and nephrogenic systemic fibrosis. J Eur Acad Dermatol Venereol. 2017;31(10):1581-1594.

10. Bidier M, Zschoche C, Gholam P, et al. Scleromyxoedema: clinical followup after successful treatment with high-dose immunoglobulins reveals different long-term outcomes. Acta Derm Venereol. 2012;92(4):408-409. 
11. Efthimiou P, Blanco M. Intravenous gammaglobulin and thalidomide may be an effective therapeutic combination in refractory scleromyxedema: case report and discussion of the literature. Semin Arthritis Rheum. 2008;38(3):188-194.

12. Sansbury JC, Cocuroccia B, Jorizzo JL, et al. Treatment of recalcitrant scleromyxedema with thalidomide in 3 patients. J Am Acad Dermatol. 2004;51(1):126-131.
13. Cañueto J, Labrador J, Román $\mathrm{C}$, et al. The combination of bortezomib and dexamethasone is an efficient therapy for relapsed/refractory scleromyxedema: a rare disease with new clinical insights. Eur $J$ Haematol. 2012;88(5):450-454.

14. Chockalingam R, Duvic M. Scleromyxedema: long-term follow-up after high-dose melphalan with autologous stem cell transplantation. Int $J$ Dermatol. 2016;55(10):539-543. 